\title{
PROTAGONISMO POLÍTICO-INSTITUCIONAL DO SUPREMO TRIBUNAL FEDERAL E COVID-19: UMA CONJECTURA A PARTIR DA ADPF 669
}

\section{POLITICAL-INSTITUTIONAL PROTAGONISM OF THE SUPREME FEDERAL COURT AND COVID-19: A CONJECTURE FROM ADPF 669}

Wilson Steinmetz ${ }^{1}$

\begin{abstract}
Resumo: Este estudo tem por objeto a medida cautelar concedida pelo Supremo Tribunal Federal na ADPF 669 que suspendeu a campanha publicitária "O Brasil Não Pode Parar". Analisam-se e discutem-se o atendimento do requisito da subsidiariedade da ADPF no caso e a existência do fato impugnado. A concessão de medida cautelar para proteger direitos e bens que já estavam protegidos por tutela de urgência deferida pela Justiça Federal do Rio de Janeiro em ação civil pública indica que o Supremo Tribunal Federal, no enfrentamento de casos relativos à Covid-19, pretendeu assumir um papel de protagonista político-institucional. A hipótese é de que essa orientação foi tomada de forma deliberada pelo Supremo Tribunal Federal ante a existência de visões e abordagens conflitantes no campo das decisões políticas, especialmente do Poder Executivo das três esferas da Federação, no enfrentamento da Covid-19. O estudo tem caráter heurístico e conjectural em direção de novos estudos que tenham por objeto o conjunto das decisões do Supremo Tribunal nos casos relativos à Covid-19.
\end{abstract}

Palavras-chave: Covid-19. Supremo Tribunal Federal. ADPF 669. Protagonismo político-institucional.

\begin{abstract}
This study has as its object the precautionary measure of the Supreme Federal Court in ADPF 669 that suspended the advertising campaign "Brazil can not stop". The compliance with the ADPF's requirement of subsidiarity in the case and the existence of the contested fact are analyzed and discussed. The granting of a precautionary measure to protect rights and assets that were already protected by urgent protection granted by the Federal Court of Rio de Janeiro in a public civil action indicates that the Federal Supreme Court, when facing cases related to Covid-19, intended to assume a role of political-institutional protagonist. The hypothesis is that this orientation was deliberately taken by the Federal Supreme Court in the face of conflicting visions and approaches in the field of political decisions, especially of the Executive Branch of the three spheres of the Federation, in the confrontation of Covid-19. The study has a heuristic and conjectural character towards new studies that have as object the set of Supreme Court decisions in the cases related to Covid-19.
\end{abstract}

Keywords: Covid-19. Supreme Federal Court. ADPF 669. Political-institutional protagonism.

Recebido em 22 de outubro de 2020 Aceito em 22 de abril de 2020

\section{Introdução}

O primeiro caso confirmado de Covid-19 no Brasil é de 26 de fevereiro de 2020. A primeira morte provocada pela Covid-19 é de 12 de março de 2020. Esses são os dados oficiais. Desde então a República Federativa do Brasil enfrenta a pandemia do novo coronavírus. São dezenas de milhares de mortes e graves repercussões na saúde individual de muitos dos contaminados sobreviventes, no sistema público de saúde e na economia.

\footnotetext{
1 Doutor e Mestre em Direito pela Universidade Federal do Paraná; Professor no Programa de Pós-Graduação em Direito da Universidade do Oeste de Santa Catarina e da Universidade de Caxias do Sul; Rua Francisco Getúlio Vargas, 1130, 95070-560, Petrópolis, Caxias do Sul, Rio Grande do Sul, Brasil; wilson.steinmetz@gmail.com; https://orcid.org/0000-0003-0519-6201
} 
A pandemia produziu impactos sobre o sistema político-institucional. Ela exigiu medidas específicas de grande envergadura do Poder Legislativo e do Poder Executivo. Do Poder Legislativo, e aqui cite-se apenas o Congresso Nacional, exigiu, às pressas, a aprovação de um marco legal regulatório para o enfrentamento da Pandemia (Lei 13.979/2020) (BRASIL, 2020b) e a aprovação do "Orçamento de Guerra" (Emenda Constitucional n. 106/2020) (BRASIL, 2020a). Do Poder Executivo, exigiu medidas regulamentares e administrativas que afetaram direitos fundamentais individuais (especialmente decretos estaduais e municipais restritivos com fundamento na Lei 13.979/2020) e aportes econômicos próprios de um período de guerra.

A Covid-19 também produziu repercussões no campo judicial. São dezenas de decisões de órgãos judiciais, do primeiro grau ao Supremo Tribunal Federal (STF), tendo por objeto questões relativas ao enfrentamento da Covid-19. Isso teve como causa não apenas os interesses econômicos e sociais de indivíduos e grupos afetados pelas medidas estatais restritivas - o que era de se esperar em uma conjuntura de crise sanitária -, mas especialmente pelas visões de como enfrentar a pandemia expressas pelo Governo da União, principalmente nas manifestações do Presidente da República em pronunciamentos formais e informais, visões quase sempre conflitantes com as de chefes do Poder Executivo dos principais estados e municípios e com as posições defendidas pela comunidade científica e pelo maioria de influentes formadores de opinião na imprensa nacional. Em síntese, as conflitantes abordagens propostas provocaram a judicialização da Covid-19.

No plano judicial, o ator principal tem sido o STF, especialmente por meio da concessão de medidas cautelares em controle de constitucionalidade por via de ação direta. $O$ caso mais significativo foi a da ADPF 672 (SUPREMO TRIBUNAL FEDERAL, 2020a). No julgamento do pedido de medida cautelar, a corte estabeleceu as principais balizas para o enfrentamento da Covid-19 no âmbito das competências federativas.

Uma das questões fundamentais que certamente será objeto de análise e debate na comunidade científica do Direito no próximo período é se o STF atuou apenas como ator jurídicoinstitucional ou também como ator político-institucional durante a pandemia do novo coronavírus. O inciso XXXV do art. $5^{\circ}$ da Constituição da República Federativa do Brasil de 1988 (CF) prescreve a regra da inafastabilidade do Poder Judiciário em caso de lesão ou ameaça de lesão a direito (BRASIL, 1988). Umas das implicações dessa previsão constitucional é a de que, se provocados, os órgãos judiciais devem decidir. As decisões podem ser mais "ativas" (ativismo judicial") ou mais "autocontidas". Quando um órgão judicial, especialmente se for a corte constitucional, decide de forma mais "ativa", está atraindo e promovendo o próprio protagonismo, não apenas em nível jurídico-institucional (deveres funcionais normativos), mas também em nível político-institucional.

A concessão de medida cautelar pelo ministro Roberto Barroso na ADPF 669 é um indício expressivo de que o STF dadas as conflitantes abordagens no âmbito da atuação dos poderes executivos da União, Estados e Municípios - deliberadamente pretendeu assumir um protagonismo político-institucional no enfrentamento da pandemia do novo coronavírus (SUPREMO TRIBUNAL 
FEDERAL, 2020b). A decisão na ADPF 669, embora monocrática, indica que o STF, orientado por uma determinada autocompreensão institucional, tomara uma posição política mais ativa e a faria valer quando provocado. Segundo essa visão, no enfrentamento da Covid-19, deveria prevalecer a visão dominante na comunidade científica ${ }^{2}$ e entre os formadores de opinião, segundo a qual a ação dos Poderes Públicos deveria se orientar pela prevenção, precaução, priorização da vida e da saúde mesmo que implicasse medidas fortemente restritivas ao livre exercício de atividade econômica, à liberdade de reunião, à liberdade de locomoção, ao livre exercício de culto, entre outros direitos.

Este breve estudo de caso não tem como objetivo alcançar conclusões gerais e definitivas sobre a atuação do STF como ator político-institucional no enfrentamento da Covid-19. É um estudo de natureza heurística e conjectural para investigações futuras mais abrangentes e exaustivas.

\section{Fatos}

A Confederação Nacional dos Metalúrgicos (CNMT) e o partido Rede Sustentabilidade ajuizaram, separadamente, no Supremo Tribunal Federal, duas arguições de descumprimento de preceito fundamental. As ações foram autuadas respectivamente como ADPF 668 e ADPF 669 e distribuídas ao ministro Roberto Barroso. Ambas indicavam como objeto de impugnação a contratação e divulgação preliminar de uma campanha publicitária do Governo Federal intitulada "O Brasil Não Pode Parar".

No plano normativo, as proponentes alegaram que a campanha publicitária violava inúmeros preceitos fundamentais da CF, a saber, os direitos fundamentais à vida (caput do art. $5^{\circ}$ ), à saúde (arts. $6^{\circ}$ e 196), à informação (incisos XIV e XXXIII do art. $5^{\circ}$, caput e $\int 1^{\circ}$ do art. 220) e preceitos fundamentais aplicáveis à Administração Pública (caput e $\int 1^{\circ}$ do art. 37).

No plano fático, a CNMT e a Rede Sustentabilidade indicavam o Extrato de Dispensa de Licitação N. 1/2020 - UASG 110319, no valor global de R \$ 4.897.855,00, tendo por objeto a "prestação de serviços de comunicação digital" com a justificativa de "disseminar informações de interesse público à sociedade, por meio de desenvolvimento de comunicação" (PRESIDÊNCIA DA REPÚBLICA, 2020).

As proponentes também informavam a existência de um vídeo preliminar cuja divulgação já estava disponível em redes sociais, sendo distribuído inclusive pelo aplicativo de mensagens WhatsApp. Referências à campanha "O Brasil Não pode Parar" também se encontravam no Instagram, Twitter e Facebook, inclusive em contas pertencentes a familiares do Presidente da República. ${ }^{3}$ Para a CNMT e Rede Sustentabilidade, a campanha publicitária desinformaria e desorientaria a

\footnotetext{
2 Em entrevista de 12 de abril de 2020, o ministro Roberto Barroso, referindo-se à medida cautelar concedida na ADP 669, declarou: "Acho que há um discurso sério e consistente pelo isolamento social vindo das autoridades sanitárias. É a valorização da ciência, que foi minha própria decisão contra a campanha [do governo], que já tinha entrado na internet, 'O Brasil não pode parar', que defendia volta ao trabalho." (CONTRA..., 2020).

3 O vídeo a que se referiram as proponentes está disponível no YouTube (GOVERNO..., 2020).
} 
população porque veicularia informações falsas sobre a Covid-19 e os riscos que ela representa para a vida, saúde individual e saúde pública. A campanha induziria os brasileiros a comportamentos que potencializariam o contágio pela Covid-19.

As proponentes pediram a concessão de medida cautelar para a suspensão da contratação e veiculação da campanha publicitária; no mérito, pediram a procedência para anular a contratação da campanha publicitária.

O ministro Roberto Barroso recebeu a ADPF 669 apresentada pela Rede Sustentabilidade por não haver dúvida sobre a existência de legitimação ativa para a propositura (partido com representação no Congresso Nacional) ${ }^{4}$ e adiou para momento posterior a apreciação da ADPF 668 da CNMT, ${ }^{5}$ porque requereria análise sobre a legitimação ativa por pertinência temática. $\bigcirc$ ministro Roberto Barroso concedeu medida cautelar na ADPF 669 proibindo a

[...] produção e circulação, por qualquer meio, de qualquer campanha que pregue que 'O Brasil Não Pode Parar' ou que sugira que a população deve retornar às suas atividades plenas, ou, ainda, que expresse que a pandemia constitui evento de diminuta gravidade para a saúde e a vida da população.

Determinou, "ainda, a sustação da contratação de qualquer campanha publicitária destinada ao mesmo fim." (SUPREMO TRIBUNAL FEDERAL, 2020b, p. 2-3).

\section{Questões constitucionais em discussão}

Trata-se de típico caso de direito constitucional. Entende-se por caso de direito constitucional aquele que se constitui de um ou mais problemas cuja decisão jurídica implica a interpretação e aplicação de dispositivos normativos enunciados no texto constitucional. A questão constitucional deste caso pode ser explicitada não em uma única questão-problema, mas em ao menos duas.

A primeira questão diz respeito aos direitos fundamentais em jogo. Pode ser assim formulada: a contratação e veiculação da campanha publicitária do Poder Executivo da União "O Brasil Não Pode Parar", no contexto do enfrentamento da emergência de saúde pública de importância internacional decorrente da Covid-19, violava os direitos fundamentais à vida, à saúde e ao acesso à informação?

A segunda questão refere-se aos preceitos fundamentais aplicáveis à Administração Pública e assim pode ser enunciada: a contratação e veiculação da campanha publicitária do Poder Executivo da União "O Brasil Não Pode Parar", no contexto do enfrentamento da emergência de saúde pública de importância internacional decorrente da Covid-19, violava princípios constitucionais

\footnotetext{
4 Art. $2^{\circ}$, I da Lei 9.882/1999 combinado com art. 103, VII da Constituição da República Federativa do Brasil.

5 "Postergo para momento posterior à oitiva das autoridades, da Advocacia Geral da União e da Procuradoria Geral da República a decisão sobre a admissibilidade da ação proposta pela Confederação Nacional dos Trabalhadores Metalúrgicos." (SUPREMO TRIBUNAL FEDERAL, 2020b, p. 5).
} 
da Administração Pública prescritos no caput do art. 37 (CF) e o mandamento segundo o qual "a publicidade dos atos, programas, obras, serviços e campanhas dos órgãos públicos deverá ter caráter educativo, informativo ou de orientação social [...]"? (\$ $1^{\circ}$ do art. 37 da CF, grifo nosso).

Em relação à primeira questão, é necessário um esclarecimento sobre umas das variáveis: acesso à informação. A questão só se justifica se o pressuposto é de que ao Poder Público, por meio de campanhas publicitárias, não basta informar ou dar acesso à informação. É imperativo que a informação seja verdadeira, correta ou autêntica.

Em relação à segunda questão, dos princípios constitucionais da Administração Pública previstos no caput do art. 37, estão em jogo os princípios da moralidade e da eficiência.

\section{Decisão e seus fundamentos}

O ministro Roberto Barroso concedeu a cautelar na ADPF 669, ajuizada pela Rede Sustentabilidade, nos termos acima descritos. Portanto, identificou a presença dos requisitos da verossimilhança do direito invocado e do perigo na demora.

No plano da verossimilhança do direito alegado, a previsão constitucional dos direitos à vida, saúde, segurança e informação impõe ao Estado não apenas o dever de prover ações e serviços (dimensão prestacional em sentido estrito), mas também o dever de não colocar os bens protegidos em risco (dimensão defensiva ou negativa).

O ministro também argumentou que, em princípio, aplicava-se ao caso o dever constitucional de as campanhas publicitárias terem caráter "informativo, educativo ou de orientação social" ( $\int 1^{\circ}$ do art. 37 da CF). Este dever constitui-se em parâmetro de aferição, em concreto, do respeito aos princípios da moralidade e da eficiência na contratação e veiculação de conteúdo publicitário pela Administração Pública.

O juízo sobre a incidência prima facie desses dispositivos ao caso em discussão, elemento justificador da concessão de cautelar, amparava-se na natureza, proporção e gravidade da pandemia Covid-19. O ministro Roberto Barroso tomou como referência empírica os dados internacionais - medidas de enfrentamento e números de casos confirmados e de óbitos - até então conhecidos relativos às experiências chinesa, italiana, espanhola e norteamericana. ${ }^{6}$ Também tomou em consideração as declarações e recomendações da Organização Mundial da Saúde, do Ministério da Saúde, do Conselho Federal de Medicina e da Sociedade Brasileira de Infectologia e as projeções do Imperial College London. Essas declarações e recomendações apontavam as medidas necessárias ao enfrentamento da pandemia e alertavam para os graves riscos e danos à vida e à saúde da população na hipótese de descontrole e avanço generalizados da Covid-19.

\footnotetext{
6 Aqui não é o caso de analisar se os dados empíricos citados eram completos e confiáveis e se a interpretação que deles fez o ministro Roberto Barroso era correta.
} 
Com apoio na jurisprudência do Supremo Tribunal Federal, o ministro Roberto Barroso também invocou os princípios da precaução e da prevenção.

Por fim, considerou evidente no caso o perigo de demora, haja vista já existir um vídeo preliminar disponível em redes sociais com potencial de veiculação ilimitado por meio de WhatsApp e Telegram.

\section{Análise e discussão críticas}

\subsection{Arguição de Descumprimento de Preceito Fundamental e subsidiariedade}

A primeira questão relevante para a análise do caso é de natureza processual. Conforme o $\int 1^{\circ}$ do art. $4^{\circ}$ da Lei 9.882/1999, "Não será admitida argüição de descumprimento de preceito fundamental quando houver qualquer outro meio eficaz de sanar a lesividade." (BRASIL, 1999). O ministro Roberto Barroso argumentou que o requisito da subsidiariedade estava "indiscutivelmente" atendido porque não haveria outra ação direta aplicável ao caso que permitisse uma decisão com efeitos erga omnes e vinculantes para todo o Poder Judiciário e para a Administração Pública de todas as esferas da Federação (SUPREMO TRIBUNAL FEDERAL, 2020b, p. 4-5).

No entanto, é discutível a afirmação do ministro de que o atendimento do requisito da subsidiariedade era "indiscutível". A concessão da cautelar na ADPF 669 (Rede Sustentabilidade) é de 31 de março de 2020. O Ministério Público Federal (Procuradoria da República no Estado do Rio de Janeiro) havia ajuizado uma ação civil pública com pedido de tutela de urgência na Justiça Federal (Seção Judiciária do Rio de Janeiro) em 27 de março de 2020 tendo por objeto precisamente o Extrato de Dispensa de Licitação N. 1/2020 - UASG 110319 e a campanha publicitária "O Brasil Não Pode Parar" (MINISTÉRIO PÚBLICO FEDERAL, 2020). No plano da tutela provisória, o Ministério Público pedia tutela de urgência para suspender a veiculação de toda e qualquer peça publicitária em redes sociais e aplicativos de mensagens. Na madrugada de 28 de março, a juíza federal Laura Bastos Carvalho deferiu a tutela de urgência para que a União se abstivesse, por quaisquer meios, de veicular peças publicitárias da campanha "O Brasil Não Pode Parar" ou qualquer outra campanha cujo teor estivesse em desacordo com as diretrizes técnicas do Ministério da Saúde (JUSTIÇA FEDERAL, 2020).

Portanto, na data da concessão da cautelar na ADPF 669 pelo ministro Roberto Barroso, já estava em vigência, há três dias, uma decisão da Justiça Federal proibindo o patrocínio e a veiculação pelo governo da União de qualquer peça publicitária por quaisquer meios (TV, rádio, jornais, revistas, sites governamentais, redes sociais e aplicativos de mensagens) sobre a campanha "O Brasil Não Pode Parar" ou campanha com fins semelhantes, que induzissem a população a relativizar os riscos e a gravidade da Covid-19. Por ser uma decisão em ação civil pública, os efeitos são gerais ou erga omnes. Assim, a coletividade já estava protegida por decisão da Justiça Federal contra um ato do governo da 
União havido como danoso ou potencialmente danoso à saúde individual, à saúde como interesse difuso e à vida.?

A decisão da Justiça Federal teve grande destaque nos principais jornais do país (versão online), redes de TV, rádios, redes sociais, blogs e site diversos de notícias. É pouco crível que o ministro Roberto Barroso, em 31 de março, não tivesse ciência da decisão da Justiça Federal do Rio de Janeiro.

Em parecer de 13 de abril de 2020, a Procuradoria-Geral da República anotou que o requisito da subsidiariedade não estava atendido por nenhuma das ADPF (668 e 669) (PROCURADORIAGERAL DA REPÚBLICA, 2020). Ou seja, havia outras ações judiciais hábeis a atingir os mesmos efeitos, haja vista que estava em questão uma campanha publicitária do governo da União e não de outros entes federativos ou de outros poderes da República. No parecer, a Procuradoria-Geral da República lembrou que em relação à lesão ao patrimônio público alegada pelo partido Rede Sustentabilidade há instrumento processual hábil e específico: a ação popular (Lei 4.717/1965). Informou que já estavam tramitando, à data do parecer da PGR, uma Ação Popular na 22a Vara Cível da Subseção Judiciária de São Paulo (n 5005009-65.2020.4.03.6100) e uma Ação Popular na 20ª Vara Federal Cível da Seção Judiciária do Distrito Federal (n 1016948-19.2020.4.01.3400).

\subsection{Controvérsia sobre a existência da campanha publicitária "O Brasil Não Pode Parar"}

O Extrato de Dispensa de Licitação N. 1/2020 (UASG 110319) indicava como objeto a "prestação de serviços de comunicação digital"; apresentava como justificativa "disseminar informações de interesse público à sociedade por meio de desenvolvimento de ações de comunicação" e informava o valor global de R \$ 4.897.855,00 e a empresa contratada. Não havia qualquer referência à campanha "O Brasil Não Poder Parar" ou a qualquer outra campanha publicitária (PRESIDÊNCIA DA REPÚBLICA, 2020).

No entanto, informalmente, como demonstrado documentalmente pelo Ministério Público Federal (Procuradoria da República no Rio de Janeiro) na petição inicial da supracitada ação civil pública, em redes sociais circulavam materiais (prints) em contas de familiares e simpatizantes do Presidente da República com referências ao "O Brasil Não Pode Parar". Também é fato apurado que havia um vídeo, com duração de 1 minuto e 27 segundos, disponível em redes sociais. A última imagem do vídeo é o logo oficial "Pátria Amada Brasil Governo Federal". É o logo do Governo Bolsonaro.

Em 28 de março de 2020, na mesma data do deferimento da tutela de urgência pela Justiça Federal que proibiu a campanha, a Secretaria Especial de Comunicação Social da Presidência da República (Secom) emitiu nota pública negando a contratação e existência da campanha publicitária "O Brasil Não Pode Parar". Acusou a imprensa de produzir e veicular "fake news".

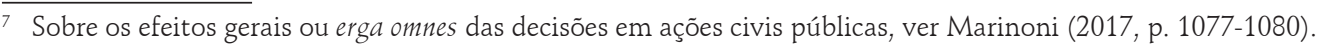


Contudo, no dia anterior (27 de março de 2020), a mesma Secom informou que o vídeo veiculado informalmente em redes sociais, inclusive pelo Senador Flávio Bolsonaro (RJ), era um vídeo experimental ainda não aprovado.

Essa descrição dos fatos e especialmente as contradições da Secom são indícios de que o governo federal planejava uma campanha publicitária tendo por objeto a Covid-19. A questão aqui, porém, é se com base nas informações fatuais disponíveis existia ou estava em curso, de fato, um ato do poder público federal contrário a preceitos fundamentais. Trata-se, portanto, de um problema de confiabilidade de juízo sobre premissas empíricas.

O ministro Roberto Barroso não teve dúvidas sobre a existência do ato do poder público, assim como a Justiça Federal do Rio de Janeiro também não teve.

Os elementos fáticos do caso apontam majoritariamente para a existência, em potência, do ato do poder público. Contudo, não se pode desconsiderar, de plano, o comunicado oficial da Secom em 28 de março de 2020, portanto, três dias antes da concessão da cautelar pelo ministro Roberto Barroso, negando a existência de qualquer campanha publicitária. É pouco provável que o ministro Roberto Barroso não tivesse qualquer informação sobre o comunicado da Secom, noticiada amplamente por jornais e sites. Assim, poderia, como já fez o Supremo Tribunal Federal, em outros casos, ter determinado, com prazo estipulado, que a Presidência da República e a Secom prestassem informações sobre a existência da campanha "O Brasil Não Pode Parar".

Antes de conceder medida cautelar na ADPF 672 (SUPREMO TRIBUNAL FEDERAL, 2020a), o ministro Alexandre de Moraes intimou o Presidente da República para no prazo de 48 (quarenta e oito) horas apresentar informações sobre as questões fáticas e jurídicas suscitadas.

Cite-se ainda como exemplo representativo a ADPF 735 (SUPREMO TRIBUNAL FEDERAL, 2020c). O Partido Verde ajuizou a ADPF 735 contra o Decreto 10.341/2020 do Presidente da República e a Portaria 1.804/2020 do Ministério do Estado de Defesa, que criaram a Operação Verde Brasil 2. Conforme argumentação do Partido Verde, a Operação provocaria um "desmonte da política ambiental", esvaziando as funções do Ministério do Meio Ambiente e de outros órgãos de proteção ao meio ambiente. $O$ protagonismo passaria a ser das Forças Armadas e haveria, assim, uma militarização da política ambiental brasileira, o que contrariaria prescrições constitucionais relativas à defesa e proteção do meio ambiente. O Partido Verde pediu a concessão de cautelar para suspender os atos normativos até o julgamento do mérito. A ministra Cármen Lúcia, relatora da ADPF 735, requisitou informações ao Presidente da República e ao ministro do Estado de Defesa sobre os atos normativos impugnados, estipulando um prazo de cinco dias. Após os cinco dias, abriu vista à Advocacia-Geral da União e à Procuradoria-Geral da República para que se manifestassem (SUPREMO TRIBUNAL FEDERAL, 2020c).

Nas ADPF 672 e 735, os ministros relatores consideraram a relevância de oportunizar ao Poder Executivo a prestação de informações, antes de uma decisão individual ou do Pleno do STF pelo deferimento da medida cautelar suspensiva dos atos normativos impugnados. Essa providência 
é harmônica com o princípio da separação de poderes, o princípio democrático e com a deferência, devida prima facie, à discricionariedade administrativa em matéria de política pública.

Em seu parecer, a Procuradoria-Geral da República (2020) manifestou-se no sentido de que a campanha publicitária não existiu. E "mesmo para os que afirmam haver existido o aludido ato, teria subsistido por breve período e, ao final, sido retirado de circulação, o que levaria, de toda sorte, a uma perda superveniente do objeto apontado nesta ADPF", argumentou o Procurador-Geral da República, Augusto Aras.

Em 7 de maio de 2020, o ministro Roberto Barroso acatou o parecer da Procuradoria-Geral da República, reconhecendo a não existência do fato e, por consequência, a perda do objeto das ADPF 668 e 669. Ambas as ações foram extintas, antes mesmo de a medida cautelar ser submetida a referendo do Pleno do STF.

\section{Anotações finais}

As ADPF 668 e 669 não atendiam o requisito da subsidiariedade. Os direitos e bens constitucionais ameaçados pelo ato governamental impugnado já estavam protegidos por uma tutela de urgência deferida pela Justiça Federal, com efeitos gerais, em ação civil pública. Essa decisão era de conhecimento público, porque fora amplamente noticiada por diferentes meios de comunicação social. É remota a possibilidade de que o STF não tivesse conhecimento da decisão.

Havia dúvidas plausíveis sobre a existência oficial do fato impugnado - a contratação e veiculação da campanha publicitária "O Brasil Não Pode Parar". A própria Secom, vinculada à Presidência da República, negou, em manifestação oficial, a existência do fato. Mesmo assim, o ministro Roberto Barroso entendeu que não era o caso de requisitar, de plano, informações ao Presidente da República e/ou à Secom. Por exemplo, poderia ter requisitado a prestação de informações em prazo determinado e exíguo, providência adotada pelo próprio STF em outros casos.

Esses dois elementos apontam para uma hipótese de elevada plausibilidade: a cautelar concedida de plano na ADPF 669 indica o propósito deliberado de posicionar o STF como um protagonista não apenas jurídico, mas também como um protagonista político no enfrentamento da Covid-19. Em um contexto de crise sanitária, com visões e abordagens conflitantes sobre o enfrentamento da crise - defendidas de um lado pelo Presidente da República, de outro por governadores, prefeitos, comunidade científica e formadores de opinião -, o STF sentiu-se compelido a tomar uma decisão que extrapolou os limites do direito processual e material posto. Uma medida cautelar concedida pelo STF em ADPF tem muito mais impacto midiático, político e social do que uma tutela de urgência deferida por um juízo monocrático de primeiro grau em ação civil pública, não obstante o objeto e os efeitos, neste caso, fossem os mesmos.

Essa decisão na ADPF 669 é coerente com a visão sustentada pelo ministro Roberto Barroso em textos acadêmicos. Segundo Barroso (2018), uma suprema corte ou um tribunal constitucional 
além de contramajoritário tem de ser representativo e iluminista; tem de ajudar a empurrar a história para frente.

Nos limites deste estudo de caso, não é possível discutir os fundamentos, as implicações e a correção político-jurídica da visão defendida pelo ministro Roberto Barroso. Com o "baixar do fogo e da fumaça provocados" pela Covid-19 no campo político-institucional, a comunidade científica do direito poderá investigar e avaliar o papel do STF no enfrentamento da Covid-19. As investigações poderão corroborar ou falsear a hipótese de que esta corte judicial deliberadamente assumiu um protagonismo político-institucional, pretendendo ser um contrapeso a visão e à abordagem sustentadas pelo chefe do governo federal.

\section{REFERÊNCIAS}

BARROSO, Luís Roberto. Contramajoritário, representativo e iluminista: os papéis dos tribunais constitucionais nas democracias contemporâneas. Revista Direito Práxis, Rio de Janeiro, v. 9, n. 4, p. 2171-2228, 2018.

BRASIL. Constituição. República Federativa do Brasil de 1988. Brasília, DF: Senado Federal, 5 out. 1988. Disponível em: https://bityli.com/sVh7y. Acesso em: 27 set. 2020.

BRASIL. Emenda Constitucional n. 106, de 7 de maio de 2020. Institui regime extraordinário fiscal, financeiro e de contratações para enfrentamento de calamidade pública nacional decorrente de pandemia. Diário Oficial da União, Brasília, DF, 8 maio 2020a. Disponível em: https://bityli.com/ NeGXV. Acesso em: 27 set. 2020.

BRASIL. Lei n. 9.882, de 3 de dezembro de 1999. Dispõe sobre o processo e julgamento da argüição de descumprimento de preceito fundamental, nos termos do $\$ 1^{\circ}$ do art. 102 da Constituição Federal. Diário Oficial da União, Brasília, DF, 6 dez. 1999. Disponível em: https://bityli.com/lVx21. Acesso em: 27 set. 2020.

BRASIL. Lei n. 13.979, de 6 de fevereiro de 2020. Dispõe sobre as medidas para enfrentamento da emergência de saúde pública de importância internacional decorrente do coronavírus responsável pelo surto de 2019. Diário Oficial da União, Brasília, DF, 7 fev. 2020b. Disponível em: http://www. planalto.gov.br/ccivil_03/_ato2019-2022/2020/lei/113979.htm. Acesso em: 27 set. 2020.

CONTRA coronavírus, STF prioriza valorização da ciência, diz Barroso. Consultor Jurídico, 12 abr. 2020. Disponível em: https://bityli.com/wtMXY Acesso em: 28 abr. 2020.

GOVERNO lança campanha "O Brasil não pode parar". [S. l.: s. n.], 2020. 1 vídeo (1 min). Publicado pelo Canal Migalhas. Disponível em: https://bityli.com/klyLn. Acesso em: 16 jun. 2020.

JUSTIÇA FEDERAL. Seção Judiciária do Rio de Janeiro. Ação Civil Pública No 501948443.2020.4.02.5101/RJ. Autor: Ministério Público Federal. Réu: União - Advocacia Geral da União. Juíza Laura Bastos Carvalho. Rio de Janeiro, 28 mar. 2020. Disponível em: https://bityli.com/truI6. Acesso em: 16 jun. 2020. 
MARINONI, Guilherme. O controle incidental na ação civil pública e na ação popular. In: SARLET, Ingo Wolfgang; MARINONI, Luiz Guilherme; MITIDIERO, Daniel. Curso de Direito Constitucional. 6. ed. rev. e atual. São Paulo: Saraiva, 2017. p. 1077-1080.

MINISTÉRIO PÚBLICO FEDERAL. Procuradoria da República no Rio de Janeiro. Ação Civil Pública com Pedido de Tutela de Urgência, PRRJ--F - 1.30.001.001365/2020-17. Rio de Janeiro, 27 mar. 2020. Disponível em: https://bityli.com/GDS8P. Acesso em: 16 jun. 2020.

PRESIDÊNCIA DA REPÚBLICA. Secretaria de Governo. Secretaria Especial de Comunicação Social. Extrato de Dispensa de Licitação N. 1/2020 - UASG 110319. Diário Oficial da União: n. 59, seção 3, p. 1, Brasília, DF, 26 mar. 2020. Disponível em: https://bityli.com/kpulC. Acesso em: 15 jun. 2020.

SUPREMO TRIBUNAL FEDERAL. ADPF 669. Relator: Ministro Roberto Barroso. Brasília, DF, 31 mar. 2020a. Disponível em: https://bityli.com/5magO. Acesso em: 15 jun. 2020.

SUPREMO TRIBUNAL FEDERAL. ADPF 672. Relator: Ministro Alexandre de Moraes. Brasília, DF, 8 abr. 2020b. Disponível em: https://bityli.com/HPTxR. Acesso em: 15 abr. 2020.

SUPREMO TRIBUNAL FEDERAL. Partido contesta uso das Forças Armadas no combate a crimes ambientais. Noticias STF, 4 set. 2020c. Disponível em: https://bityli.com/8kYQs. Acesso em: 12 set. 2020 . 
